\title{
Expression of IER3 in Primary Hepatocarcinoma: Correlation with Clinicopathological Parameters
}

\author{
Zhong Liu ${ }^{1,2}$, Xin-Mei Wang ${ }^{2}$, Tong-Fu Jia ${ }^{2}$, Yi Zhai ${ }^{2}$, Ling-Yan Sun ${ }^{2}$, Yu-Ping \\ Cheng $^{2}$, Yue-Min Zhang ${ }^{2}$, Shi-Hai Liu ${ }^{3}$, Jun Liang ${ }^{3 *}$
}

\begin{abstract}
Background: Studies indicate the immediate early response gene 3 (IER3) is involved in many biological processes. Recently, it was discovered that IER3 plays an important role in tumorigenesis and tumor progression. Thus it may be a valuable biomarker in tumor. This study was designed to investigate the expression status of IER3 in primary hepatocarcinoma (PHC) and correlation with clinicopathological parameters. Materials and Methods: Real-time PCR was performed to evaluate the expression levels of IER3 in 62 pathologically diagnosed human PHC specimens. Results: A statistically significant association was disclosed between the expression of IER3 and P53 mutant protein (short for P53), Ki-67, EGFR and the biggest diameter, differentiation grade of tumor.Conclusions: This work is the first to shed light on the potential clinical usefulness of IER3, as an efficient tumor biomarker in PHC.
\end{abstract}

Keywords: Immediate early response gene 3 - primary hepatocarcinoma - expression - tumor progression

Asian Pac J Cancer Prev, 16 (2), 679-682

\section{Introduction}

Immediate early response gene IER3, also known as IEX-1, was discovered by Charles in 1993, which is a stress-inducible gene involved in the regulation of cellcycle progression and apoptosis (Charles et al., 1993; Kondratyev et al., 1996). Previous studies demonstrated that IER3 was expressed in a variety of human tissues (Feldman et al., 2001) and exert an important role in regulating apoptosis and cell growth through a positive or negative way, depending on the types of cells and stimuli (Wu, 2003). The role of IER3 in regulating apoptosis was controversy in several studies. IER3 plays a key role in cellular resistance to apoptosis, such as the activationinduced cell death in T cells (Zhang et al., 2002; Zhang et al., 2003). However, IER3 significantly promotes apoptosis induced by death ligand or by DNA-damaging agents in other cell types (Arlt et al., 2001; Schilling et al., 2001; Arlt et al., 2003; Osawa et al., 2003). IER3 expression in tumor cells has been speculated to affect tumor development through the observations of the roles of IER3 in vitro cell culture systems. It is reported that IER3 is highly expressed in many tumor tissues and it means that there maybe close relationship between IER3 and tumor progression and tumorigenesis (Hu et al., 2004; Nambiar et al., 2004; Dilley et al., 2005; Yang et al., 2006). The exact molecular mechanisms for IER3 under normal and pathophysiological conditions are complicated and remain largely unknown.

In the present study, the IER3 expression was examined in tumor tissue from PHC patients to determine whether the IER3 expression is correlated with other clinicopathological parameters.

\section{Materials and Methods}

\section{Sample selection}

Sixty-two pathologically conformed human HCC specimens without preoprative therapy, such as chemotherapy and radiotherapy, were collected at the pathology department of Zibo center hospital. All specimens were fixed in bufered $4 \%$ para formaldehyde, embedded in paraffin. The procedures were performed according to the national institutes of health guidelines regarding the use of human tissues and the study was approved from the review board of the ethics committee of Zibo center hospital.

\section{RNA isolation and cDNA conversion}

RNA was extracted from FFPE tissues using the Relia prep TM FFPE total RNA Miniprep system and based on the manufacturer's recommendation (Promega, 1002). Briefly, six shaving $10 \mu \mathrm{m}$ thick from a paraffin block of tissue were deparaffinized by washing the tissue with xylene. Tissue was then digested in protease $\mathrm{K}$ and allowed to adhere to the RNA biding column.

${ }^{1}$ Medical College, Qingdao University, ${ }^{3}$ Department of Medical Research Center, Department of Oncology, the Affiliated Hospital of Qingdao University, Qingdao, ${ }^{2}$ Department of Chemotherapy, Department of Pathology, Zibo Center Hospital, Zibo, Shandong, China *For correspondence: liangjun818@126.com 
The columns were incubated in Dnase and washed with alcohol before RNA was eluted in $50 \mu \mathrm{l}$ of water. RNA was quantified apectrophoto metrically and only samples with sufficient quantity and appropriate optical (OD260/280 ratio=1.8-2.0) were used for subsequent analysis. Samples that did not meet the RNA quality and quantity requirements were excluded from the study. For cDNA synthesis, $4 \mu \mathrm{g}$ total RNA and random 6 primers $(100 \mu \mathrm{m}) 50$ pmol, Oligo dT primer $(50 \mu \mathrm{m}) 25 \mathrm{pmol}$ were incubated at $65^{\circ} \mathrm{C}$ for $10 \mathrm{~min}$. Reverse transcription was performed using the M-MLV (promega M1705) and followed the specifications of the manufacturer and were incubated at $37^{\circ} \mathrm{C}$ for $1 \mathrm{~h}$ followed by $75^{\circ} \mathrm{C}$ for $10 \mathrm{~min}$.

\section{Real-time quantitive PCR (R-T PCR)}

R-T PCR were performed with the SYBR green real time-PCR (MJ research, PTC200) and using $2 \mu \mathrm{l}$ of the cDNA mixture and $10 \mu \mathrm{l} 2 \mathrm{x}$ RT mix in a $20 \mu \mathrm{l}$ reaction. The BROAD light cycler real-time PCR system (Linegene K FQ D-48A) was used. The PCR parameters were 3 min for $95^{\circ} \mathrm{C}$ and 40 cycles of $95^{\circ} \mathrm{C}$ for $10 \mathrm{~s}$ and $60^{\circ} \mathrm{C}$ for $1 \mathrm{~min}$. Gene expression levels were calculated during the logarithmic amplification phase by determining the initial mRNA copy number using the standard curve. Amplification of each gene specific fragment was conformed by examination of peaks of melting curves. To further control for equal amount of total RNA loading, parallel examination of the house keeping genes Actin was quantified in each sample.

\section{Immunohistochemical evaluation}

The expression of EGFR, P53, Ki-67,AFP in the tumor tissue specimens was assessed by immunohistochemistry. 4- $\mu$ m-thick sections were cut from formalin-fixed, paraffin-embedded (FFPE) tumor tissue specimens. The sections were deparaffinized in xylene and rehydrated in a graded ethanol series and then endogenous peroxidase activity was blocked with $\mathrm{H}_{2} \mathrm{O}_{2}$ in methanol. After the sections were pretreated with heat for antigen unmasking, immunohistochemistry was performed using the Ventana automated immunostainer (Ventana medical systems, Tucson, AZ, USA) with antibody (1:100 dilution) and secondary antibody (Beijing Zhongshan Company, China). The slides were then counterstained with hematoxylin. The expression of EGFR, P53, Ki-67, AFP was scored as negative or positive, according to the intensity of stained tumor cells compared with that of the surrounding connective tissues. When at least $20 \%$ of tumor cells show staining intensity stronger than that of the surrounding connective tissues, the tumor was regarded as positive; otherwise it was scored as negative. All specimens were evaluated independently by two investigators without any knowledge of the patient characteristics.

\section{Statistical analysis}

Student's t-test was used to determine statistical significance between two sample means. And the chisquared test was used to analyze significant associations between the expression of IER3 and P53, ki-67, EGFR and other clinicopathological features. The SPSS statistal package version 13.0 (SPSS, Inc., Chicago, USA) was used for the statistical analyses. A p-value less than 0.05 was chosen to indicate statistical significance between two samples.

\section{Results}

The expression of IER3 was assessed by real time PCR in tissue specimens from 62 patients with PHC. The patients included 51 males and 11 females of age ranging from 33 to 83 years. Among the 62 patients, IER3 expression was positive in 38 tissue specimens (61.3\%) and negative in $24(38.7 \%)$. Table 1 shows the relationship between the IER3 expression and other clinicopathological factors. Using the chi-square test of independence, IER3 and P53, ki-67, EGFR expression were found to be significantly associated (Table 1). Approximately $74 \%$ of IER3-positive cases also expressed ki-67, while fewer than $17 \%$ of IER3 negative cases stained positive for ki-67. On the contrary, no such correlation was observed between IER3 and AFP, with a $p$-value of 0.06. The tumor biggest diameter, differentiation grade was also found to be associated with IER3 expression. While the age, gender of patient and tumor thrombus was not observed of such association.

\section{Discussion}

Recent studies have characterized the functional interaction of IER3 with several signaling pathways, such as NF- $x$ B, PI-3K/Akt, ERK. NF- $x$ B/rel proteins, p53 and oncogene c-Myc are critical transcription factors involved in coordinating cellular decision-making events in response to external stimuli. Consensus sequences for binding these three transcription factors are found in the

Table 1. Correlation Between the IER3 Expression and Clinicopathological Factors in 62 PHC P atients

\begin{tabular}{|c|c|c|c|c|c|}
\hline \multicolumn{2}{|c|}{ Factor } & \multicolumn{3}{|c|}{ No. of patients } & \multirow[t]{2}{*}{$P$} \\
\hline & & total & $\begin{array}{c}\text { IER3 } \\
\text { Positive } \\
(n=38)\end{array}$ & $\begin{array}{c}\text { IER3 } \\
\text { Negative } \\
(n=24)\end{array}$ & \\
\hline \multirow[t]{2}{*}{ Age(years) } & $\operatorname{High}(\geq 65)$ & 18 & 11 & 7 & \\
\hline & $\operatorname{Low}(<65)$ & 44 & 27 & 17 & 0.99 \\
\hline \multirow[t]{2}{*}{ Gender } & Male & 51 & 29 & 22 & \\
\hline & Female & 11 & 9 & 2 & 0.12 \\
\hline \multirow[t]{2}{*}{ P53 } & Positive & 27 & 21 & 6 & \\
\hline & Negative & 35 & 17 & 18 & $0.02 *$ \\
\hline \multirow[t]{2}{*}{$\mathrm{Ki}-67$} & Positive & 32 & 28 & 4 & \\
\hline & Negative & 30 & 10 & 20 & $0.00 *$ \\
\hline \multirow[t]{2}{*}{ EGFR } & Positive & 24 & 19 & 5 & \\
\hline & Negative & 38 & 19 & 19 & $0.02 *$ \\
\hline \multirow[t]{2}{*}{ AFP } & Positive & 19 & 15 & 4 & \\
\hline & Negative & 43 & 23 & 20 & 0.06 \\
\hline \multicolumn{6}{|c|}{ Differentiation Grade } \\
\hline & Low & 34 & 25 & 9 & \\
\hline & High-media & 28 & 13 & 15 & $0.03 *$ \\
\hline \multicolumn{6}{|c|}{ Biggest diameter } \\
\hline & $\geq 5 \mathrm{~cm}$ & 25 & 11 & 14 & \\
\hline & $<5 \mathrm{~cm}$ & 37 & 27 & 10 & $0.02 *$ \\
\hline \multicolumn{6}{|c|}{ Tumor thrombus } \\
\hline & Yes & 22 & 13 & 9 & \\
\hline & No & 40 & 25 & 15 & 0.79 \\
\hline
\end{tabular}


promoter region of IER3 gene that can either suppress or induce apoptosis in a cell and stimulus-dependent manner. Interestingly, NF- $x \mathrm{~B} /$ rel-mediated activation of IEX-1 expression was synergized by $\mathrm{p} 53$, but strongly inhibited by c-Myc in a dose-dependent fashion (Huang et al., 2002). It may explane the varing effects of $\mathrm{p} 53$ on IEX-1 expression in different cells.

Interestingly, it has been proposed that IER3 may enhance cell proliferation under favorable growth condition in the absence of cellular stresses, but may facilitate apoptosis under stressed conditions, such as serum starvation. Because the tumor microenvironment often involves stressed conditions unfavorable for tumor cell growth, such as a lack of growth-promoting factors (cytokines), nutrition and oxygen. IER3 may function as a pro-apoptotic factor in tumor cells and thereby limit tumor progression (Sasada et al., 2008; Han et al., 2011). But, necrosis and inflammation, which is a stimuli, is common in tumor centre. And the cells in the margin of the tumor may have enough oxygen and nutrition. These may be the reasons for the high expression of IER3 in this study.

Several studies about IER3 expression in variable human tumors was controversy. Yang et al. reported an enhanced expression of IER3 in atypical ductal hyperplasia or ductal carcinomas in situ and invasive carcinomas of the breast (Yang et al., 2006). Zhang et al. reported that IER3 may prevent the activation induced cell death of T-cells (Zhang et al., 2002; Zhang et al., 2003). Ishimoto et al. found that IEX-1 suppressed apoptotic damage in human intestinal epithelial Caco- 2 cells induced by coculturing with macrophage-like THP-1 cells secreting TNF- $\alpha$ (Ishimoto et al., 2011). In contrast, IER3 also plays a role of pro-apoptotic effect in other types (Xiao et al., 2008; Hamidi et al., 2012). Distinct reduction of IER3 expression was found in human colorectal cancers (Nambiar et al., 2004), breast cancers (Hu et al., 2004) and pancreatic cancers (Sasada et al., 2008).

Additionally, it is found that IER3 may be a tumor therapy target for it can be affected by several drugs. For example, IER3 expression was stimulated by hydroxyltamoxifen, that the degree of increase was greater in resistant cells (Semlali et al., 2004). Bruheim S et al. reported that small interfering RNA-mediated gene silencing of IER3 sensitized the human osteosarcoma cell line OHS to treatment with 4-hydroperoxyifosfamide (Bruheim et al., 2009). The increased P53 protein bind the promoter region of IER3 gene, which repress the transcription and result in down-regulation of IER3 gene expression. Transcriptional factor P53 was up-regulated after the addition of $\mathrm{As}_{2} \mathrm{O}_{3}$ in human osteosarcoma cell MG63 (Xiao et al., 2008). It is reported that IER3 upregulation is correlated with a decrease level of intracellular ROS and low TNFR1 expression on malignant lymphocytes. Targeting IER 3 could be of interest for the development of future therapeutic strategies for patients with Sezary syndrome (Akilov et al., 2012).

Positive of P53 mutant protein, ki-67and EGFR means tumor cell grow faster. Consistent with the studies mentioned above, The present study showed that positive expression of IER 3 in tissues from PHC patients was well correlated with P53, ki-67, EGFR, tumor biggest diameter and differentiation grade. These results suggested that IER3 is an valuable independent biomarker for PHC. To our knowledge, this is the first report to analyze the IER3 expression in PHC tissues and to demonstrate the relationship between the IER3 expression and other clinicopathological parameters. These results suggest that IER3 may be involved in promotion of the progression of PHC.

\section{Acknowledgements}

This work was supported by grants from the national nature science foundations of China (Grant No. 81372632 and 81402579), the special funds of post doctoral innovation projects of Shandong province of China (Grant No.201303063) and the application of post doctoral funds of Qingdao City, Shandong province of China (Grant No.20130118).

\section{References}

Akilov OE, Wu MX, Ustyugova IV, Falo LD Jr, Geskin LJ, (2012). Resistance of Sezary cells to TNF- $\alpha$ - induced apoptosis is mediated in part by a loss of TNFRl and a high level of the IER3 expression. Exp Dermatol, 21, 287-92.

Arlt A, Grobe O, Sieke A, et al (2001). Expression of the NFkappa B target gene IEX-1 (p22/PRG1) does not prevent cell death but instead triggers apoptosis in Hela cells. Oncogene, 20, 69-76.

Arlt A, Kruse ML, Breitenbroich M, et al (2003). The early response gene IEX-1 attenuates NF-kappaB activation in 293 cells, a possible counter-regulatory process leading to enhanced cell death. Oncogene, 22, 3343-51.

Bruheim S, Xi Y, Ju J, Fodstad O, (2009). Gene expression profiles classify human osteosarcoma xenografts according to sensitivity to doxorubicin, cisplatin and ifosfamide. Clin Cancer Res, 15, 7161-9.

Charles CH, Yoon JK, Simske JS, Lau LF, (1993). Genomic structure, cDNA sequence and expression of gly96, a growth factor-inducible immediate-early gene encoding a short-lived glycosylated protein. Oncogene, 8, 797-801.

Dilley WG, Kalyanaraman S, Verma S, et al (2005). Global gene expression in neuroendocrine tumors from patients with the MEN1 syndrome. Mol Cancer, 4, 9.

Feldmann KA, Pittelkow MR, Roche PC, et al (2001). Expression of an immediate early gene, IEX-1, in human tissues. Histochem Cell Biol, 115, 489-97.

Hamidi T, Algul H, Cano CE, et al (2012). Nuclear protein 1 promotes pancreatic cancer development and protects cells from stress by inhibiting apoptosis. J Clin Invest, 122, 2092-103.

Han L, Geng L, Liu X, et al (2011). Clinical significance of expression in ovarian carcinoma. Ultrastruct Pathol, 35, 260-6.

$\mathrm{Hu}$ Y, Sun H, Drake J, et al (2004). From mice to humans: identification of commonly deregulated genes in mammary cancer via comparative SAGE studies. Cancer Res, 64 , 7748-55.

Huang YH, Wu JY, Zhang Y, Wu MX, (2002). Synergistic and opposing regulation of the stress-responsive gene IEX-1 by p53, c-Myc and multiple NF- $x \mathrm{~B} / \mathrm{rel}$ complexes. Oncogene, 21, 6819-28.

Ishimoto Y, Satsu H, Totsuka M, Shimizu M, (2011). IEX-1 suppressed apoptotic damage in human intestinal epithelial Caco- 2 cells induced by coculturing with macrophage-like 
THP-1 cells. Biosci Rep, 31, 345-51.

Kondratyev AD, Chung KN, Jung MO, (1996). Identification and characterization of a radiation-inducible glycosylated human early-response gene. Cancer Res, 56, 1498-502.

Nambiar PR, Nakanishi M, Gupta R, et al (2004). Genetic signatures of high- and low-risk aberrant crypt foci in a mouse model of sporadic colon cancer. Cancer Res, 64 , 6394-401.

Osawa Y, Nagaki M, Banno Y, et al (2003). Expression of the NF-kappa B target gene X-ray-inducible immediate early response factor-1 short enhances TNF-alpha-induced hepatocyte apoptosis by inhibiting Akt activation. $J$ Immunol, 170, 4053-60.

Sasada T, Azuma K, Hirai T, et al (2008). Prognostic significance of the immediate early response gene X-1 (IEX-1) expression in pancreatic cancer. Ann Surg Oncol, 15, 609-17.

Schilling D, Pittelkow MR, Kumar R, (2001). IEX-1, an immediate early gene, increases the rate of apoptosis in keratinocytes. Oncogene, 20, 7992-7.

Semlali A, Oliva J, Badia E, Pons M, Duchesne MJ, (2004). Immediate early gene X-1 (IEX-1), a hydroxytamoxifen regulated gene with increased stimulation in MCF-7 derived resistant breast cancer cells. J Steroid Biochem Mol Biol, 88, 247-59.

Wu MX (2008). Roles of the stress-induced gene IEX-1 in regulation of cell death and oncogenesis. Apoptosis, 8, 11-8.

Xiao T, Zhu W, Yao MJ, et al (2008). Study on the mechanism of transcriptional regulation of IEX-1 gene induced by AS2O3 in human osteosarcoma MG-63. Progress Biochem Biophys, 35, 828-33.

Yang C, Trent S, Ionescu-Tiba V, et al (2006). Identification of cyclin D1- and estrogen-regulated genes contributing to breast carcinogenesis and progression. Cancer Res, 66 , 11649-58.

Zhang Y, Schlossman SF, Edwards RA, et al (2002). Impaired apoptosis, extended duration of immune responses and a lupus-like autoimmune disease in IEX-1-trans-genic mice. Proc Natl Acad Sci USA, 99, 878-83.

Zhang Y, Finegold MJ, Porteu F, Kanteti P, Wu MX, (2003). Development of T-cell lymphomas in Emu-IEX-1 mice. Oncogene, 22, 6845-51. 